\title{
The Appropriation of the Work of Art as a Semiotic Act
}

\author{
Francis Édeline and Jean-Marie Klinkenberg
}

\begin{abstract}
A work of art can be defined as a section of space (visual, auditory, tactile, etc.) that has been assigned a particular status. It is not our intention to define this status-philosophical aesthetics has been addressing this issue for centuries. Rather, we aim to pinpoint the mechanisms in virtue of which this section of space is isolated and bestowed with the status in question. Such a move requires the action of a certain instance-hence the emphasis we put on the interactive character of the process. We shall pay particular attention to the type of sign called 'index,' which plays a pivotal role in this affair.
\end{abstract}

Keywords Index $・$ Visual perception $・$ Expectations pragmatics $・$ Catasemiosis

\section{Two Methodological (or Epistemological) Preconditions}

\subsection{The Appropriation of Statements as a Semiotic Practice}

With undeniable methodological relevance, the structuralist thought affirmed to raise a true wall dividing on one side, semiotic systems and, on the other side, the world with its performing actors. This is the principle of immanence. It was a purely methodological and temporary separation: its purpose was to eliminate ontological presuppositions, common psychologism, and reckon on elements that, since they are closed in on themselves, are controllable. The profitability of that separation turned out to be spectacular and allowed the development of highly sophisticated descriptive instruments. However, semiotics does not have the vocation to indefinitely put off the moment to question the relation between the world and meaning (cf. Groupe $\mu$ 2011, 2015).

Unfortunately, recent developments in semiotics have hardly broken up with the immanentist doctrine and keep setting aside the question of the contact point

F. Édeline $(\bowtie) \bullet J .-M$. Klinkenberg

Groupe $\mu$, University of Liège, Liège, Belgium

e-mail: venus33@ skynet.be; jmklinkenberg@ulg.ac.be 
between the world and the languages, regarding both the origin of these languages and the active part they play within society.

We will note that, for instance, "the semiotics of practices," which emerged recently, is still full of a glossocentrism already defended by Barthes. As Fontanille explains, "If practices can be described as semiotic, it must be possible to assimilate them to a language" (2010, p. 10). However, he also says that the units of the expression plan of practices are not accessible but through diverse episemiotic manifestations (first and foremost verbal—but also gestural and physiognomic ... ). Indeed, these units could not be "deduced retrospectively from a transformation observed in the end" for the reason that a practice would be "an open process, both as regards its starting and its end point, which therefore would not provide a basis for a confrontation between an initial and a final situation" (ibid.), "unlike a textualized action" (Fontanille 2011, p. 132). Hence the decision not to study the practices in action but instead to seize them from the statements that describe them. But the argument is debatable: linguistic statements are as open as factual processes. And their closure is not given from the outset but instead is the product of the methodological decision made by the linguistic discipline. Now, such a decision can also be made in the case of processes.

Visual semiotics - to which we will give priority here, in the wake of our previous contributions (Groupe $\mu$ 1992) —still suffers from these orientations and, until recent years, has largely neglected the stock of rules that preside over the social, pragmatic use of visual statements. Traditionally, it gives priority to an immanent point of view: the observation of phenomena is done in such a way that, in order to describe them, it is not necessary to resort to elements outside the system. The most important thing is that the description of the system can make do with its own internal consistency, which makes the description appropriate for its object.

We intend to break up with this point of view: the problem of the appropriation of the work of art will be here considered as a practice.

If semioticians such as O. Le Guern (e.g. 2005, 2009, 2011) and A. Beyaert "have studied images or art installations taking into account the types of showrooms inside of which there is a painting or a series of paintings [ ... ] the purpose of those studies was never to study the way the museum institution approves and valorizes the images by making them, precisely, artistic" (Maria-Giulia Dondero, unpublished quotation). Since we are keen to describe this validation and practice-which we already started to do in a previous work (Groupe $\mu$ 2002) - that appropriation will be described:

(a) in terms of actualization: every user mobilizes a semiotics in an individual act, and within that semiotics, every unit undergoes a concrete actualization performed by the user at a given time and in a given place;

(b) in cultural terms: any semiotics is a collective, intersubjective reality that can be defined as a set of rules in effect within a community of users; 
(c) in terms of pluricodical utterances (cf. Klinkenberg 2000): the appropriation of the work involves not only the modalities of reading of that work, ${ }^{1}$ but also the rules regarding the use of the space it is part of;

(d) in terms of action: the appropriation is a dynamic act, unfolding in time and causing multiple effects. ${ }^{2}$

Of course, such a program could not be entirely covered in the following paper. We will content ourselves with the outline of some of these various issues.

\subsection{Genetic Aesthetics and Instituted Aesthetics}

The presentation that follows could be unfolded in two ways:

- According to a both logical and physiognomic scheme. Logical because of a growing complexity: going, for instance, from the description of the perceptual contrasts underpinning the bestowal of meaning upon the world to the aesthetic judgment that results from this. As its complexity increases, the artistic specificity of this schema will increase accordingly. Indeed, at the bottom of this scale, the described phenomena (contrasts, to keep our example) have no artistic specificity.

- According to a chronological scheme that would follow the steps of the appropriation of the work. If, for example, I decide to go in a museum, I consider the existence of truly artistic artifacts and look for them. Here, expectation comes first, which orients and assigns a goal to perception. It is, for instance, directed toward what we will call hereinafter the indexes designating the work, such as the frame; it leads one to give priority to the content of the frame, the other objects of perception being set aside as irrelevant (the electric plug of the showroom, its custodian); scrutiny and meaning attribution come afterwards.

None of the branches of that alternative can be favored. If the question of artistic specificity may be more easily addressed within the second scheme, the latter bypasses some of the non-specifically artistic phenomena described in the first; yet these phenomena cannot be eliminated from the presentation because their role is crucial for the perception of the work. Moreover, the second scheme leads to consider the artistic world as an already established world: we appropriate a work of art that is already there, with its institutionalized status. In contradistinction to this, the first scheme has a generative character: the artistic appropriation took place when we decided to direct our gaze toward certain sectors of the perceptive field and, during the anasemiotic process (cf. Groupe $\mu$ 2011), to assign a specific status

\footnotetext{
${ }^{1}$ That might be very open, as we know. For the cases of extreme openness, those Eco calls ratio difficilis, the principle can be formulated as follows: the work creates its own code.

${ }^{2}$ This is what we call catasemiosis (Groupe $\mu$ 2013, in press A).
} 
Table 1 Aesthetic semiogenesis

\begin{tabular}{l|l}
\hline Operations & Results of the operations \\
\hline Selection and discretization & Contrasts and closure \\
\hline Scrutiny & Barysemiotization \\
\hline Mobilization of expectations & Semiotization 1 \\
\hline Attribution of status and interpretation & Semiotization 2 \\
\hline
\end{tabular}

to them-thus constituting a segment of reality as a work of art. In the present case, it consists in identifying a domain in which the utterances can be categorized. This decision can be described as a conquest and part of aesthetic pleasure may be linked to that expansion of the semiotic field. It suggests that there must be a genetic aesthetics, just as there is a genetic epistemology for Piaget.

Therefore, we will reconcile both approaches, while focusing our attention on the first one and saving the second one for later works, according to the following table (Table 1):

\section{The Functional Space of the Work}

The process of appropriation of the work is based on two significant phenomena: (a) a section of the global visible space captures the viewer's attention and is thus both assigned salience and semiotic prominence (this is what we will term 'barysemy'), and (b) the demarcated section is attributed a specific cultural status.

Capturing the attention is a phenomenon that occurs several times in the global process, therefore the above scheme can decidedly not be chronological.

\subsection{Focusing the Attention}

\subsubsection{Sensory Contrasts and Barysemy}

The process of selection is based on a fundamental property of all visual utterances that derives from the very mechanisms of perception: a division in both the perceptual and the intelligible field that produces the paradigms of the units of both the expression plane and the content plane (cf. Groupe $\mu$ 1992, 1998). This division goes hand-in-hand with a differentiation. In terms of space, this differentiation designates a central space and a peripheral space separated by a boundary (which may be fictional), i.e., it established an opposition between inside and outside. We have already showed in other works (Édeline 1991; Groupe $\mu$ 1992, 2011) that this selection was equivalent to what we called "elementary visual knowledge," that is 
to say, the possibility to distinguish within a field between two different translocal qualities, separated by a discontinuity. ${ }^{3}$

That opposition can of course be semanticized in a host of ways by specific norms (as it is showed by the examples of family space or national space). Besides, the manifestation of the separation might have various degrees.

Naturally, a work of art will not only present one but a plurality of translocal qualities. But this mere word (translocal) immediately designates a certain rate of homogeneity of the considered sub-space. The discontinuity-which René Thom calls a catastrophe, and which is enhanced by the perceptual system-divides the field into two entities and itself displays a shape. The functioning of perception is such that this shape is not considered to have an independent existence but is assigned either to one of the entities or the other-or, exceptionally, to both.

Here, the important thing is that the perceived areas are organized into a hierarchy: we are dealing with the classical dialectics of figure and ground. Now, this organization into a hierarchical structure is not self-evident. Why is privilege given to the inside? In a museum, why do we not focus our attention on the thermostats as much as on the statues? The phenomenon is complex, and can only be clarified by the use of our concept of index, which will be developed further on (cf. Sect. 2.2). At this place, let us simply underline the physiological basis of the mechanism. Faithful to our assumption of naturalization, we will suggest (cf. Groupe $\mu$ 1989, 1992) that the reason is the reproduction of the organization of the retina: the fovea, the only area with a lot of cones where vision is clear, is located in its center. Here we are dealing with the production of a barysemy, or semiotic densification of the central area.

The fact that meaning results from grouping information (cf. Groupe $\mu$ 2011) suggests that the level of concentration of that meaning may vary in time or space. Goodman had already noticed it, talking about the "semantically dense" and "syntactically dense" character of the work of art (1968). However, it is possible to give a rigorous content to what was only a concetto for Goodman ${ }^{4}$ and, particularly, provide a good explanation for it.

The variation of density of meaning is indeed determined by two series of phenomena, some of which are natural while others are cultural. The latter-in the forefront of which stands the index-will be analyzed in Sect. 2.2.1. But, as we are about to see in a moment, the distinction between natural and cultural phenomena is not always so clear.

\footnotetext{
${ }^{3}$ One may imagine counterexamples to this. Take a Diego Rivera-like mural fresco in the middle of which a window opens allowing an inside to be seen. Such examples do not disprove the rule, however: either the inside is considered as a noise, and does not take part in the appropriation of the work, or it is semanticized and takes part, and is therefore interpreted as an inside within an inside.

${ }^{4}$ Goodman does not give any definition of the notion of density, which remains a metaphor here; he generalizes the phenomenon so that it embraces the whole work even though the density areas vary (sometimes they are central, sometimes they are peripheral); moreover he seems to impart an intrinsic aesthetic value to density.
} 
Here, let us concentrate on the first type of factors, which are not mentioned by Goodman. The areas where meaning gets denser are constructions where two subfactors take action: the properties of the organs of perception and those of the object of that perception.

(a) First sub-factor: the properties of the organs of perception.

Once again, we will use human vision to illustrate the first sub-factor. We know that vision does not uniformly grasp the characteristics of the field it is applied to. The resolving power of the eye, or the solid angle corresponding to the light rays hitting only one receptor cell of the retina, is worth $200 \mathrm{~s}$ of arc in the fovea (that is to say $1 \mathrm{~m}$ seen at $1 \mathrm{~km}$ ); the resolution is better in the center of the retina but the beam of attention is approximately $1^{\circ}$ of angle and determines the central area of the visual field, the only sector in which maximum details are perceived. Thus, we cannot talk about a barysemiotizing area. ${ }^{5}$ However, in fact, that zone goes beyond $5^{\circ}$ of angle thanks to a very efficient double process which consists in endlessly moving the point of scrutiny over the surface to explore. That mechanism has two variants. In the first one, the numerous rapid movements performed by the eye (the so-called REM, rapid eye movements) scan the area randomly. But in the other one, the eye is guided by voluntary movements in a chosen direction. ${ }^{6}$ These decisions made possible thanks to the mobility of the organ are passed on by other decisions. They are enabled by the mobility of the whole body and can take place within strategies of barysemiotization (for example, getting closer to the work of art or stepping away from it). As can be seen, we have gradually moved from physiological to cultural phenomena.

(b) Second sub-factor: the properties of the objects of perception.

The second natural sub-factor is the structure of the perceived field: we are entitled to surmise that meaning concentrates around catastrophes, i.e., around discontinuities which themselves are opposed to areas of continuity, according to the fundamental dipole principle (cf. Groupe $\mu$ 2015). In our Traité du signe visuel (1992), we highlighted that in a line drawing, the area of barysemy is the contour, a place that separates two areas less rich in information; that is to say, once again, separated into dipoles. We can represent the correspondence between two visual segments (for example, an impressionist painting and its corresponding line drawing) by means of a transformation that can be modeled as a double differentiation: instead of being diluted on all the perceived surface, the meaning concentrates at the exact point where the value of the signal changes. What we have described in the visual field can similarly be found in the

\footnotetext{
${ }^{5}$ As to the vast peripheral area, it is specialized in the perception of the global environment and movement. This area has rarely been exploited by artists (for an example of such an exploitation, cf. Klinkenberg 2004).

${ }^{6}$ When it comes to neural wiring, the nerve cells are interconnected laterally in order to create receptive fields that contain a center and a periphery with antagonistic responses.
} 
linguistic field, where the signal engineers clearly showed that a barysemiotical core is to be found at the initials of words.

It is important to highlight that none of these factors can found barysemy on their own: in compliance with our basic thesis (cf. Groupe $\mu$ 2011, 2015), meaning - and thus the density of that meaning-is the product of the interaction of these two factors. $^{7}$

In the case of the perception of a work of art, the hedge effect is one of focusing one's attention whose immediate corollary is, once again, the production of a barysemy. The viewer is obliged to produce meaning on the spot: museum, gallery, private wall covered with drafts, public wall with graffiti. In return, the delimitation ensures or enhances a perceptual, intellectual, and psychological "comfort." Importantly, the perturbing interferences with the environment outside the index are inhibited.

As we will discuss below (Sects. 2.4 and 5), part of the artistic techniques developed by human beings will precisely consist in playing with the closure effects.

\subsubsection{Expectations and Semiotization}

Expectation has indissolubly linked rational and emotional aspects.

It is misleading to present the viewer (and his/her organs of perception) as a blank photographic plate. As first, Gestalt psychology and then cognitive psychology and semiotics have showed that the act of looking is a dialectic in which preexisting codes are confronted with external stimuli. Therefore, there is an interaction between the stimuli and the patterns. This suggests a double movement, going from the world to a semiotic subject and vice versa. In one direction, the stimuli are assessed in the light of a model available to us. Along the other direction, the model is modified by the data provided by perception and observation. This double movement, of course, reminds us of the assimilation-accommodation couple in genetic psychology, and it is crucial to understand the attribution of meaning. When inspecting a painting, the viewer takes interest in the manner of expression adopted by the painter. For example, the viewer may try to capture information about the painter and his personality instead of information about the motif (what distinguishes a woman painted by, say, Botticelli from one painted by Raphael, Klimt, Modigliani, or Schiele).

When they take pragmatic decisions, the viewers are driven by their idiosyncrasy. Besides, they already are so at the mere level of perception (perception has different

\footnotetext{
${ }^{7}$ All of this indicates that barysemy is measurable: in the visual field, the density of meaning is the number of dipoles perceptible for a surface unit. Of course, we can also measure the variation of density in time, taking into account the evolution of the number of dipoles or that of the surface. We can symmetrically consider barysemy as the opposite of repetition, which brings it also into the scope of the calculable (at least theoretically).
} 
styles). But they are also driven by the knowledge they have about the environment and the indexical codes valid in this environment, as we will discuss in Sect. 2.2.2.

\subsection{Artifacts}

Some artifacts enhance the specificities of both areas: center and periphery. This is especially the case for the indexes, on which we will elaborate below, and which will eventually allow us to address the specificity of artistic receiving.

\subsubsection{A General Theory of the Index ${ }^{8}$}

The Peircian terminology has only one term for two very different phenomena that should be carefully distinguished. We will note them index $x_{a}$ (arbitrary) and index $x_{m}$ (motivated) respectively. The index $\mathrm{m}_{\mathrm{m}}$ is based on a "natural" contiguity relation not provoked by man, whereas the index $\mathrm{x}_{\mathrm{a}}$ is a cultural and conventional sign. In the following, we are only concerned with indexes $\mathrm{a}_{\mathrm{a}}$.

The index $\mathrm{x}_{\mathrm{a}}$ is a semiotic device with a double property. (i) It focuses the attention of the receiver of the indexical act on a determined portion of space (and, more particularly, it detaches an object within that space) that therefore becomes the indexed. (ii) It attributes a certain status to that indexed. A familiar example: a pointed finger; but the label, the cover page, the stage, the pulpit, etc. exert the same effect.

That device mostly unfolds in the longest semioses and is subject to a significant cultural investment: the type of reference it elicits is eminently conventional.

Focusing the attention on a determined portion of space is nothing but contributing to the discontinuity that segments the perceptive field, or establishing that segmentation. In any event, the index takes part in shaping the segmentation we discussed in Sect. 2.1.1. In the case of works of art, that form assumes a true but limited importance, that of "formats:" portrait, landscape, marine, tondo, lockets... ${ }^{9}$

The index only works in the presence of the designated portion of space, in such a way that its definition activates the idea of contiguity, or rather of neighborhood, a word borrowed from topology, which therefore is neutral as to the actual physical

\footnotetext{
${ }^{8} \mathrm{Cf}$. Groupe $\mu$ in press B.

${ }^{9}$ The format is the product of two determinations: that of the organs of perception (binocularity explains the relative universality of the horizontal format and that of the shapes of the theme and thus of the indexed (a standing subject will be treated according to the vertical axis).
} 
Table 2 Structure of the index

\begin{tabular}{l|l|l}
\hline & Indexation & \\
\hline Indexing & $\rightarrow$ & Indexed \\
\hline pointed finger & a) focalization & object \\
\cline { 1 - 1 } pointer & b) attribution of status (ex.: work of art, social function ....) & exit door \\
\cline { 1 - 1 } label & & sculpture \\
\cline { 1 - 1 } badge & & individual \\
\hline cover... & & book... \\
\hline
\end{tabular}

distance between what will be defined hereinafter as the indexer and the indexed. ${ }^{10}$ The nature of the objects destined to become indexes is very variable. They may be linguistic, for example, with shifters and connectors. ${ }^{11}$ The writing, the spatial manifestation of language, frequently has an indexical function too. ${ }^{12}$ There are other explicit indexes, such as the /dash/, indicating the equivalence of the linguistic portion of a statement and of its iconic portion, the /tail of the speech balloon/, or the frame. However, the index may not be manifested through a specialized sign: the indexical function is thus assumed simply by spatial proximity.

Founded on contiguity, the index always mobilizes three elements: (i) the actual indexical sign (/pointed finger/, /label/... ) or indexer, (ii) the designated portion of space, or indexed, and (iii) the relation to the latter that the former institutes (by designating it, giving it such and such status, etc.) or indexation. The index therefore presupposes a semiotics of space: in order for the indexer to designate a portion of space, that indexed space must be perceived as a homogeneous unity, distinct from its surroundings: for example, a building or object, even a fuzzy set of trees or clouds (Table 2).

This semantics of the indexed is determined by three series of factors.

(i) The above-mentioned perceptual factors.

\footnotetext{
${ }^{10}$ That explains why indexes ${ }_{\mathrm{a}}$ often get mixed up with indexes $\mathrm{m}_{\mathrm{m}}$ (cf. Klinkenberg 2000), especially for the followers of the Peircian tradition. But the space neighborhood that is applied here is not the same as in the indication, where it is causal.

${ }^{11}$ The referent of the shifters varies according to three series of variables: (1) the couple enunciator/enunciatee, (2) the time of the enunciation, (3) the place of the enunciation. The term "connector," which has been controversial, globally designates linguistic tools expressing syntactic, logical, semantic links between two portions of statements. One of the linguistic properties of the connectors is that some of them may sometimes link portions of statement, sometimes a statement and its enunciation (external connection).

${ }^{12} \mathrm{Cf}$. Klinkenberg 2008; Groupe $\mu$ 1995. Examples: /store fronts/, /titles/ of books or pictorial works, /names/ of museum halls, of classrooms, or of congress, /badges/ of staff or participants of these congresses, /names/ of a television presenter appearing at the bottom of the screen, /labels/ of cans, /names/ of deceased people on graves ... If we find the mention /"museum"/ on an edifice, the index connects the linguistic signified "museum" and the whole structured space volume located in the background where figures the expression and designates the quality ("museum") attributed to that portion of space.
} 
(ii) Different types of sectorial semantics but still founded on the semiotization of space (architectural semantics, landscape semantics, etc.). We mentioned that the designated space had to be perceived as homogeneous; yet the knowledge of that homogeneity is itself provided by cultural rules: delimited aspect of volumes or surfaces, etc. That semiotics of space is still insufficient right now in spite of Édeline's suggestions (2013). We can claim that there are two categories of places:

(a) strictly delimited places: either they are enclosed-the museum, the gallery, the performance hall, but also the library, the classroom, the church-or they are open but resting on strict semantics (the pedestal, the stage);

(b) vaguely delimited places: in this way, without the need to enclose, Finlay sanctifies the whole space around which is its Great Turf; the space surrounding a museum is vague, but it itself makes a living statue close to its entrance count as a piece of body art.

(iii) Social praxes: reading a book, visiting a museum, visiting a sacred place.

\subsubsection{Index and Appropriation}

When it comes to praxes, one should take this into account:

- The index, which creates (or triggers) an utterance, is an utterance itself. And as an utterance, it has an enunciatee and an enunciator. While being a device producing enunciation, it has itself been enunciated.

- The index is a performative utterance; it has an illocutionary force. It has been defined as follows: it is "an order to focus one's attention to a given space sector."

- The enunciator has therefore a performative purpose, the enunciatee has his expectancies, and one or the other might be a person (or people) or an institution (the artistic institution, for instance).

Without that being a general rule, indexation often has the effect of giving a status of sign to the indexed. This is why it is so important for the problem we are addressing here. In that specific case, its role consists in triggering the semiotic decision. To do so, it disqualifies the indexed object as an object and re-qualifies it as an utterance belonging to a certain type of speech. For instance, some indexing objects such as the label, the pedestal, or the beam of a lamp in a museum can turn any indexed object into a work of art; the same lamp at the theatre, the stage, the circle constituted by the audience in the street arts make a show out of what attention is focused on; the store front disqualifies the exposed object-for example, the bottle of perfume in a store front is disqualified as a bottle whose content can be usedto re-qualify it as a sample of a category of commercial goods. In each case, the indexed has been given the status of icon: the item in the store front is there for all the items that can be found in the store which it may validly represent as an icon. Globally, all the indexed objects that are awarded the status of sign are subjected 
to a disqualification-requalification process. ${ }^{13}$ The precise direction taken by the requalification movement depends on grids governing indexation-the store front of an art museum imparts the status of unique object at a piece of work; the store front of the Natural History Museum imparts the status of sample; the store front of a shop imparts the status of commercial sample or of unique precious object-in compliance with rules that may be flexible and complex. ${ }^{14}$

It is easily observed that the indexes, in their first function consisting in centering, simply parallel the perceptive factors: they create an effect of closure and barysemy, both at an overarching level (the space through which the viewer moves) and at a subordinate level (the space the viewer has visually access to). The separation of space that they produce reinforces the aspects of the two areas: on the one hand, centrality, and peripherality on the other. We have thus been able to demonstrate that a specific type of index - the frame (cf. Groupe $\mu$ 1989, 1992)-functions as a counterpart to visual perception whose mechanism was described above (Sect. 2.1.1.), playing, as the latter, on the division between the central vision area and peripheral areas. And that also applies to any other indexicalized space.

The viewer is driven, as we described in Sect. 2.1.2., by his/her knowledge about the environment and the prevailing indexical codes in vigor, a knowledge that is clearly socially stratified. Knowing that we are in the house of an art lover or in a museum triggers evidently specific attitudes, for instance, a very precise direction for the semiotic decision. These reactions may be actions (as we will see it hereinafter). In that quest for meaning, the viewer is equipped with pre-existing types that he/she projects on the stimuli.

It is the factor of social praxis that implies that if we take a walk in a non-strictly delimited space, we can still identify a work of art, even though there is no index as strictly socialized as a label or a frame. This is the case with Finlay (where the only index is not the presence of a label but a simple stone carrying Dürer's monogram), or Giuseppe Penone's Vowel Tree in the Tuileries Garden. All of this clearly shows the relevance of cultural and social competences, which determine the expectations.

\subsection{Contextualization}

If the index can mobilize motivated signs, as in the evoked examples of icons, the fact remains that it is in itself an arbitrary sign: the type of reference it arouses is purely conventional, presupposing the semiotics of space.

\footnotetext{
${ }^{13}$ Here, Duchamp's ready-made can satisfy our need for example.

${ }^{14}$ The /green XL-sweater of a certain design/ in a storefront can mean that, within the store, we will find "green sweaters of that particular design in all sizes," "sweaters with that design and size but in other colors," "some sweaters," even "some clothes." Of course, these codes can be badly implemented, ignored, or even suspended. In the latter cases, disqualification ends: that's the example of the storekeeper who sells his/her item in storefront dispossessing it of its iconic status.
} 
Needless to say that these spaces can be articulated both in a centripetal and centrifugal way: let us think about the museum sequence, wing or floor, hall, wall, frame... Relations of subordination, superordination, and coordination between these spaces are established. They are the three syntactic relations that we can distinguish in visual semiotics:

- Subordination: the museum hall, subordinated to museum-building;

- Superordination: the museum-building, superordinated to the hall;

- Coordination: the halls, coordinated between one another.

The articulation of the homogeneous spaces (i.e., experienced as homogeneous) and thus the working as so many units within vaster complexes follows cultural rules, too. This is the reason why the indexical inscription /museum/ can appear not only on the building but also on a flagpole located several meters from the building.

The relation between this semiotics of space and its functionalization through indexes also meets another cultural code: it is one thing to identify a space as homogeneous, and possibly articulate it in sub-spaces; it is another to give, thanks to calculation, a specific value to both that space and the indexical sign itself.

That sign can have a synecdochic value, and can therefore be an ostensive $\operatorname{sign}^{15}$ : this is the case for a frame making up the logo of a gallery or a museum, a painting by a particular painter, or a sample of his/her stylistic specificities (for example, a drawing taken from Miro's work to announce an exhibition about him).

The articulations and relations we have just discussed give every element of the spatial utterance, indexical or not, some specific signified. In the case of indexical signs, consider the widely different examples of a poster announcing an exhibition and the entrance of the hall where it takes place. In the spatial articulations mentioned above, every stage can have its own signified. The /museum/ refers to the general signified "works of art," the /wing/ or /floor/ may invoke the "century" or "school" of the considered type of art, the /hall/ may invoke the "individuality" of that century or school, the /wall/ a "production period" of that individuality, the /frame/ the particular utterance made by that "production period." Thus we are clearly dealing with pluricodical utterances, where the purpose of the pluricodical aspect is to ventilate the identified elements between different semiotic categories. ${ }^{16}$

\footnotetext{
${ }^{15}$ As its name suggests, the ostensive sign "shows." But not in the way the index does, which is in a relation of neighborhood with the showed object: here, the signifier is the shown object itself (or its icon). The ostensive sign is therefore an element highlighted to synecdochically represent one or several members of the category to which it belongs. In simple terms, it is a sample.

${ }^{16}$ In that complex, one empirical object can be included in the composition of many signs as stimulus, and can therefore be sometimes an object to be emphasized, sometimes an indexical sign —only when it does not share both status at the same time. Let us consider the frame, which often has an indexical status, but which may sometimes be seen as a fraction of the work itself, even as a work of art in its own right (see the numerous examples studied in our rhetoric of frame: Groupe $\mu$ 1989, 1992).
} 


\subsection{Stylistic and Rhetoric of the Indexation}

In Sect. 2.1.1, we saw that the index produced a barysemy and a perceptive comfort which is nothing but a saturation of the enunciatee's expectations.

Yet part of the artistic techniques developed by humanity consists in playing with these norms. Those techniques can sometimes head towards the extreme reinforcement of the closure effect produced by the index and sometimes towards its annihilation. An example of the first case is given by the Druidic Triple Precinct studied by Guénon, and an example of the second one is given by Finlay and his Great Turf. ${ }^{17}$

The observations that have been made concerning the perceptive comfort of the viewer are illustrated a contrario by certain approaches. Mondrian wanted to use the painting simply as an "element of division of the wall" (Pleynet 1977, p. 138), that is to say that instead of isolating it in its frame, he wanted to take it out from it. One may also remember the memorable example from the Documenta of Kassel in 2002, where a huge empty frame was erected outside, facing the landscape. We can also think about the confusion caused by the apparition of the circle theatre, which modified and diminished the separation between the actors and the audience.

\section{Strategies of Positioning: Four Configurations}

Another step of the appropriation process consists, for a viewer, in looking for the optimal place to examine the selected piece of work and move on to the anasemiosis that he/she judges appropriate. Centering, which was discussed above, is already a positioning. But here, we are considering more precisely the strategies that result from the evoked social praxes.

For a start, it is interesting to notice that the optimal place has mostly been predetermined by the enunciator in an extremely precise way. Some famous frescoes painted on church domes have such anamorphoses that only one location allows a satisfying view (example: Trionfo del nome di Gesù, on the ceiling of the Gesù Church, by Il Baciccio); and the geometric perspective of Brunelleschi and Alberti requires a unique viewpoint, although the perceptual mechanisms of compensation and constancy allow, to a certain extent, some distancing from that optocenter. Conversely, Byzantine mosaics played on a shimmer, a scintillation of the golden tesserae, in such a way that the appropriate view suggested a moving viewer.

\footnotetext{
17 "Environmental art is another form of protest which inserts the piece of work within the environment by deleting the frame surrounding it (thus, its separation) and, consequently, makes it unlimited. Dürer's Great Piece of Turf is encircled by a frame which delimits its influence to its immediate surroundings. However, it is impossible to precise where the reconstitution of that Great Turf in Ian Hamilton Finlay's garden ends" (Édeline 2005, p. 33).
} 
Beside the Fixity vs. Movement dichotomy, there is another fundamental structure: Frontality vs. Laterality. The front view seems more or less to be the general rule, but it also has specific modalities. El Greco's elongated figures, that some assign to the "ecstatic lens" (Eisenstein 1980), may also be interpreted simply as taking into account how things appear when you perceive them from below.

The distance between the eye and the piece of work is a third critical factor, in such a way that a third axis must be taken into account: Remoteness vs. Closeness. That distance of perception does not correspond at all with the positioning of the painter during his/her work, the painter having to either move or imagine the effect of a remote contemplation. Pissaro is credited with the rule that places the optimal position at three times the diagonal of the work. However, such rigidity is not appropriate for all utterances. For example, Rothko's huge paintings require the construction of halls of adequate height and perspective (cf. Groupe $\mu$ 1994).

That alleged norm is particularly irrelevant in the case of bistable utterances, which require both proximal and distal vision at the same time, a technique epitomized by the Impressionists. We can certainly examine their stains or dotted lines very closely, but such proximal vision generally does not elicit any iconic content: that content is exclusively plastic. But a recomposed vision is obtained when the viewing distance becomes such that the solid angle that subtends two or several adjacent stains is inferior to the minimum angle of discrimination. The latter is the function of the eye optics and of the dimension of the colored receptors: it measures $0.017^{\circ}$. Then, we can calculate that if the stains of the painter have a $2 \mathrm{~mm}$ diameter (such as in Signac's Breakfast), one has to place oneself at at least $1.8 \mathrm{~m}$ to obtain the effects of luster or recomposition by additive color sought by the artist, while Pissaro's rule would require $4.4 \mathrm{~m}$. An appropriate distancing allows for the perception of two levels, a plastic one and an iconic one, fully permitting the exploitation of the icono-plastic interaction (cf. Groupe $\mu$ 1992; Parret 2008). ${ }^{18}$ Thus the Remoteness vs. Closeness axis determines three segments: the plastic zone, the icono-plastic zone and the iconic zone.

A fourth and less evident structure also plays a role: the Tandem vs. Mirror opposition. The spatial relations between a viewer and the objects of the world are indeed influenced by the intrinsic orientation of these objects (cf. Vandeloise 1986). An object with such an orientation presents a front and a back in such a way that we have the feeling we are in front of it or at its back, depending on which face it presents. We will say that we have either a mirror or a tandem perception. The intrinsic orientation of objects informs their representations. Besides, a paintingunlike a window, for instance-is also an oriented object which faces us: we

\footnotetext{
${ }^{18}$ It is a different story for some quite marginal pieces of work, where two iconic readings are possible and without any immediate relation between one another. Apart from the famous case of anomorphosis in Holbein's Ambassadors, which suggests two viewpoints laterally isolated, there are also Arcimboldo's Baroque compositions, where fruits, fishes, vegetables, etc. are put together to compose a head when you take a global view. Between 1937 and 1939, Dali painted many paintings of that type, among which we can name Face of Mae West Which May Be Used as an Apartment.
} 
stand in front of it as in front of a mirror. In some cases, the painter struggles against that orientation by representing a character from behind (i.e., Caspar David Friedrich's famous Rückenfigur), which elicits in us a tandem attitude. Landscapes are ambiguous as regards this parameter.

These examples show that the viewer's positioning is important, and that the artist implicitly expects the viewer to be placed in the expected location. This is a true power of the utterance because it triggers a complex motor activity, cybernetically regulated by vision. Now, we must look deeper into that power.

\section{Appropriation and Catasemiosis}

Saussure also defined semiotics as the "discipline that studies the life of signs within social life." But if the sign is a condition for communication, it is not sufficient to place it upstream from that communication. One must also remark that it extends its action beyond the communicative act itself. Signs do have a use. They further action. In this way, if meaning emerges from experience, it also leads to experience. This is its double corporeality. Taking this corporeality and the processes of enunciation that reflect this property seriously implies that one ceases to consider utterances as pure meanings.

The piece of work does not escape the rule: whether it is an utterance or piece of discourse, it certainly manifests an ethos, aptly laid bare by the analysis of styles (cf. Groupe $\mu$ 1995), but it is also a means to act upon the world and others. We therefore cannot study the appropriation of the work without adding a pragmatic aspect to that study, pragmatics being the part of semiotics that considers the sign as an act. This is what we call catasemiosis, a counterpart to anasemiosis (cf. Groupe $\mu$ in press A, 2015).

By presenting signs not only as the product of fixed relations between signifiers and signified within a closed system, but also as the product of constantly revived relations between objects, utterances, and enunciative instances, and by admitting the actions and habits within these interpretants, the pragmatic approach acknowledges the interpreter and his/her action on the world, just like the action of the sign on the interpreter.

It would take too long to discuss the necessary condition of both these actions here, namely interpretation. That approach can be formalized in a tripartite diagram which accommodates the structure of the interpreted utterance, the grid of interpretation, and the interpreting instance, a schema that we have exposed at the Paris colloquium on The Adventures of interpretation (Groupe $\mu$ 2008). To conclude here, we will place ourselves after the interpretation. Like any semiotic utterance, the artwork has an illocutionary function, and it tends to cash out in an action. While talking about the functional space of the artwork in terms of an obligation to produce meaning, we were indeed insisting on such an illocutionary force.

We would like to make clear that the codes implemented here are stratified. For one social group, the identification of a /museum door/ will represent an "invitation 
to come in," even a "moral imperative;" for others, it will represent an "interdiction to come in." There are many other catasemiotic examples: purchase or resale of works, purchase of reproductions, by-products or catalogues; laceration of works or other manifestations of bad mood; writing articles of artistic criticism, scholarly studies or treaties on visual semiotics; copies, attempts to imitate or improve previous works; reveries, ecstasies, nervous breakdowns, depressions or altered states of mind; excitement, militancy and conversation; religious conversion and other drastic changes of life...

Among all these effects, studied typically by sociology but which can also be approached by semiotics, we may detach the following one: the artwork, just like any other utterance, is a means to modify its partakers' representations and modes of action. In its rhetorical aspect, it proceeds to a reorganization of categories coming from experience by suggesting new ways of carving up what is conceivable; it makes the system evolve through the production of new relations between units and therefore through the production of new units. As an utterance that modifies the rules of the grids on which it is based, it serves a powerful heuristic function (cf. Groupe $\mu$ 1994; Klinkenberg 2000).

\section{Conclusion: From Semiotics to Aesthetics?}

We are aware that our remarks, even though they were formulated within the context of a largely conceived semiotics, do not go into the heart of the matter: the specificity of the work of art. We only touch upon very general conditions of the appropriation of that piece of art.

Have we reached the limits of our discipline? Semiotics as it exists for now seems quite unable to grasp the aesthetic specificity. It allows one to reach a certain point; a point much farther than classic semiotics allowed, which essentially developed descriptive devices. The essential part of it is still to be finished. By the way, it is a problem we already encountered with literature and that we discussed in our Rhétorique de la poésie (Groupe $\mu$ 1977): rhetorics, that was born in the wake of structuralism was, without question, a significant contribution to poetics, insofar as it could describe some of the required conditions for a given text to be considered as literary; but it still could not manage to lay down the sufficient conditions for this, in other words it was incapable of grasping the literary specificity. Our answer to this was the Triadic Model. The latter was certainly a semiotic device, just as the cardinal notion of mediation, which implies that we have somewhat re-incorporated the artistic into semiotics. Decisive achievements in that discipline must be sought somewhere else.

On the other hand, the legitimacy of a project consisting in developing a phenomenology of the work of art could be called into question. And, as a consequence, the very concept of "artwork" could itself be rejected: why should there be an artwork? It cannot be denied that the work of art has a status and a function: its purpose is to arouse feelings, impressions, produce knowledge, create 
communion, guide the action or be an action. Its identification, however, still rests upon an autonomisation process (to which semiotic processes such as indexation contribute), and that autonomisation deserves to be questioned for it is a product and is not self-evident.

Indeed, there is an aesthetic apprehension of the world, or a beauty of nature. The latter must certainly be correlated to the aesthetic apprehension of the work of art in the context of a general aesthetic apprehension. From an evolutionary perspective, what we call beautiful today might have been caused by the immemorial habit of looking at a world where the sky is blue and blood is red, by the urge that we have to counter the effects of time, and many other such determinants, constituting in the end an intersubjective framework of apprehension. Our feeling of beauty could reflect our adaptation to these universal constraints and be tuned to them. A whole research program in semioaesthetics is therefore launched, which applies not only to works of art but to the world as well. In the context of the present research, the problem is to track down the specificity of the work; in other words, it is to trace the limit between plain anasemiosis and artistic anasemiosis.

A major part of contemporary artistic practices questions that limit which has simultaneously a phenomenological and institutional aspect. What happens if we abolish that limit? On one side, there is Finlay's Great Turf, which extended art to the dimensions of the world, where the Sacred Grove imparts the sacred aspect to the entire world. On the other side, conceptual art does exactly the opposite: it introduces the limit in a place where we do not expect it to be, by introducing a urinal in a museum ${ }^{19}$ or a simple string in a gallery. In both categories, our categories themselves are questioned.

Indeed, the categories have been developed in order to organize the raw data of experience and to canalize its infinite variation, various stabilizations ensuring their permanency while guaranteeing their plasticity. However, in spite of that solidity, categories can still fail to account for certain experiences. Such experiences are then said to be new, like the categories whose refinement they ignite. These recategorizations can be described as moments in a series of cycles of balance and un-balance. In semiotic words, one of the functions of art is certainly to contributelike science does, but in the context of another praxis- to that constant game of re-categorization.

Open Access This chapter is distributed under the terms of the Creative Commons Attribution Noncommercial License, which permits any noncommercial use, distribution, and reproduction in any medium, provided the original author(s) and source are credited.

\footnotetext{
${ }^{19}$ Duchamp was illustrating conceptual art avant la lettre, with a clear conscience of what he was doing. His declarations leave no doubt about that (Jouffroy 1974, p. 24 sq).
} 


\section{References}

Édeline, Francis. 1991. Sur la connaissance visuelle. Théorie, Littérature, Enseignement 9: 97-112. Édeline, Francis. 2005. Les Embrayeurs cosmiques. Formules 9: 29-47.

Édeline, Francis. 2013. Morphologie des espaces mentaux. Degrés 154: b1-b24.

Eisenstein, Serguei Mikhailovitch. 1980. Cinématisme. Peinture et cinema. Brussels: Éditions Complexe.

Fontanille, Jacques. 2010. L'Analyse des pratiques: le cours du sens. Protée 38(2): 9-19.

Fontanille, Jacques. 2011. L'Analyse du cours d'action: des pratiques et des corps. Semen 32: $131-158$.

Groupe $\mu$. 1977. Rhétorique de la poésie: Lecture linéaire, lecture tabulaire. Brussels: Complexe.

Groupe $\mu$. 1989. Sémiotique et rhétorique du cadre. La Part de l'œil 5: 115-131.

Groupe $\mu$. 1992. Traité du signe visuel: Pour une rhétorique de l'image. Paris: Le Seuil.

Groupe $\mu$. 1994. Tensions et médiations. Analyse sémiotique et rhétorique d'une œuvre de Rothko. Nouveaux actes sémiotiques 34-36: 5-27.

Groupe $\mu$. 1995. Style et communication visuelle. Un produit de transformations. Protée 23: 29-36.

Groupe $\mu$. 1998. Voir, percevoir, concevoir. Du sensoriel au catégoriel. Voir 16: 28-39. Reprinted in Ateliers de sémiotique visuelle, ed. Anne Hénault and Anne Beyaert, 65-82. Paris: Presses Universitaires de France.

Groupe $\mu$. 2002. L'Appropriation de l'œuvre d'art comme acte sémiotique. Technê 15: 49-55.

Groupe $\mu$. 2008. L'Aventure des modèles interprétatifs, ou la gestion des résidus. In Les Aventures de l'interprétation, ed. Anne-Marie Houdebine, Valérie Brunetière, Sémir Badir, and Jean-Marie Klinkenberg, 22-35. Actes du Colloque international "Sémiologie 2005." Paris: Laboratoire DynaLang.

Groupe $\mu$. 2011. Pourquoi y a-t-il du sens plutôt que rien? Abrégé de sémiogénétique. Annales des sémiotiques 2: 281-313.

Groupe $\mu$. 2013. Sémiotique de l'outil. Anasémiose et catasémiose instrumentées. Signata. Annales des sémiotiques. Annals of Semiotics 4: 411-438.

Groupe $\mu$. In press A. Du sens à l'action, de l'anasémiose à la catasémiose. In Mélanges offerts à Pierre-Yves Raccah. Leuven: Academia-Bruylant.

Groupe $\mu$. 2015. Principia semiotica. Aux sources du sens. Brussels: Les Impressions nouvelles

Groupe $\mu$. In press B. Théorie de l'index.

Jouffroy, Alain. 1974. Les pré-voyants. Brussels: La Connaissance.

Klinkenberg, Jean-Marie. 2000. Précis de sémiotique générale. Paris: Le Seuil.

Klinkenberg, Jean-Marie. 2004. Le Signe plastique contre l'idéologie de l'œil. Deux expériences du corps. Visio 9(1-2): 293-302.

Klinkenberg, Jean-Marie. 2008. La relation texte-image. Essai de grammaire générale. Bulletin de la Classe des Lettres. Académie royale de Belgique 19: 21-79.

Le Guern, Odile. 2005. Rhétorique d'une mise en espace: parcours d'une exposition temporaire. Protée 33(2): 31-40.

Le Guern, Odile. 2009. Visite réelle ou visite virtuelle: complémentarité et concurrence de deux modes de parcours. In De l'expérience Multimedia, ed. Nicole Pignier, 151-163. Paris: Lavoisier.

Le Guern, Odile. 2011. De l'espace du parcours à l'espace du savoir. MEI 32: 113-124.

Parret, Herman. 2008. La Rhétorique de l'image: quand Alberti rencontre le Groupe $\mu$. In Figures de la figure: Sémiotique et rhétorique générale, ed. Sémir Badir and Jean-Marie Klinkenberg, 143-154. Limoges: Presses universitaires de Limoges.

Pleynet, Marcelin. 1977. Système de la peinture. Paris: Le Seuil.

Vandeloise, Claude. 1986. L’Espace en français. Sémantique des prépositions spatiales. Paris: Le Seuil. 